\title{
Determining a priority order between thermic utilization processes for organic industrial waste with LCA
}

\author{
V. Mannheim \& Z. Siménfalvi \\ University of Miskolc, Department of Chemical Machinery, Hungary
}

\begin{abstract}
The persistent organic pollutants (POPs) waste take the main place in the group of organic industrial waste and the residues of the POPs waste generated in the processes of the chemical industry. There are green chemistry methods and some other treatment approaches for decreasing the quantity of the organic industrial waste, but currently thermic treatment processes are the most popular alternatives. This paper summarises thermic utilisation processes with a comparison between the different technologies, stressing factors affecting their applicability and operational suitability. The Life Cycle Assessment (LCA) can play an important role in such research. With the application of LCA for the Waste-to-Energy (WtE) technologies, their economic and environmental efficiency can be determined. Their advantages and disadvantages are examined in such a multi-component matrix. The LCA software GaBi 5 Professional is the basis for life-cycle impact assessment. The research can set up prognoses and models with LCA analyses and the conscious application of scientific methods, which can offer a prognosis for untested situations. While examining the above viewpoints, it worked out a new mathematical method which, in addition to the LCA, takes time and probability into consideration with the combination of a programming language, and which may mark a new direction for solutions and decision making in waste management. Despite the fact that chemical industry and environmental protection are closely interlocked, there is fairly poor national and international professional literature available about the two connected professions.
\end{abstract}

Keywords: POPs waste, life cycle assessment, thermic treatment processes, GaBi 5 professional software, new mathematical model. 


\section{Introduction}

Recently, there has been a growing call for the quantity of organic industrial waste and transition of waste management systems to Waste-to-Energy (WtE) or Energy-from-Waste (EfW) processes. The persistent organic pollutants (POPs) wastes used oils, waste with content of PCB/PCT and pesticide wastes; take the main place in the group of organic industrial waste and the residues of the POPs waste generated in the processes of the chemical industry. The chlorination of biphenyl by PCBs can lead to the replacement of 1-10 hydrogen atoms by chlorine. The chemical formula can be presented as $\mathrm{C} 12 \mathrm{H} 10-\mathrm{nCln}$, where $\mathrm{n}$ is the number of chlorine atoms in the molecule. The PCBs are chlorinated hydrocarbons that are manufactured commercially by the progressive chlorination of biphenyl in the presence of a suitable catalyst. Depending on the reaction conditions, the degree of chlorination can vary between 21 and $68 \%$ $(\mathrm{w} / \mathrm{w})$. The theoretically possible number of different PCTs is several orders of magnitude greater than the number of PCBs, but in practice, as with PCBs, PCTs are sold on the basis of their physical properties, which depend on the degree of chlorination, and not their chemical composition.

Related to the incipient environmental demands and the reduction of risks, there are two main principles that are practical to follow:

(1) Modification of the industrial process with green chemistry methods (primary technology)

(2) Working out and optimization for the treatment of POPs waste (secondary technology).

This article would provide new information to the second research trend related to the thermic treatment methods. There are green chemistry methods and some other treatment approaches for decreasing the quantity of the organic industrial waste (the most expedient environmental aids are the usage of lowcontaining waste processes), but currently thermic treatment processes are the most popular alternatives. In order to choose the best suitable treatment of organic industrial waste, it is indispensable to compare the possible different methods of thermal treatments and prioritise them by environmental, energetic and economic effects. It is not easy to establish a clear advantage/disadvantage order even among the traditional combustion technologies, not to speak of setting up an order for the new alternative thermic methods, which are considered to be blind spots in the area of waste management. This research can set out alternatives and models with the help of LCA methods, which can extend a prognosis and priority for $\mathrm{WtE}$ technologies. The environmental and economic method, Life Cycle Assessment (LCA) can play an important role in such research. These could be the most innovative methods in the area of environmental management. With the application of this method for the thermic processes and technologies, their energetic, economic and environmental efficiency can be determined. With the use of LCAs it can be possible to determine a priority order, not just among each waste processing method but also among thermic utilization processes. Although there is already a well known waste-management hierarchy, this study may change that. This research 
simultaneously covers the areas of environmental protection, waste management, and environmental management. One has to realize the lack of national and international literatures for each of these areas, and this is especially true for their interconnected areas.

\section{Methodology, goal and scope of the research}

The first step of this research is to compare the available WtE technologies, which may differ significantly. Nowadays, incineration is the most widely used process, so it is worth comparing with the new thermic technologies. They can be mainly distinguished from traditional incineration by the fact that in their case the treatment of waste occurs with little or no oxygen present. Comparing the prevalence of new thermic technologies to incineration shows that the utilisation of these alternatives is low, and only few reliable data on emissions are available for the time being. There is no reason to suppose that toxic emissions will differ from those of a conventional incinerator. In practice it is often unclear what emissions will be involved, and what sort of residues will be produced. It is possible that, due to certain technical features of new thermic technologies, their emissions can be considered to be better than incineration emissions, but it is not correct to say that the new thermic technologies are better than incineration in terms of their emissions performance. The main advantages are useful endproducts, which can be utilised as materials and also energetically. The energy efficiency of WtE plants can be measured by comparing the electrical energy produced with the energy content of the waste. The conversion of wastes into secondary energy sources results in cleaner and more efficient processes. The second step is to set up life cycle assessment models of the WtE technologies. Their advantages and disadvantages are examined in such a multi-component matrix. The LCA software GaBi 5 is the basis for life-cycle impact assessment. The LCA results are analyzed with regard to life-cycle segments and as a functional unit of energy consumption and/or the recoverable energy that can be used (Pehnt [1]).

\section{Determination of the thermic treatment processes}

The possible energetic utilisation can be carried out by incineration, cracking (pyrolysis or gasification) and plasma technology, or parallel flow incineration (in equipments). The following sections discuss the most frequently used thermochemical technologies for WtE (Helsen and Bosmans [2], Young [3]). These are:

1) Incineration: full oxidative combustion;

2) Gasification: partial oxidation;

3) Pyrolysis: thermal degradation of organic material in the absence of oxygen;

4) Plasma-based technology: combination of (plasma-assisted) pyrolysis /gasification of the organic fraction and plasma vitrification of the inorganic fraction of waste feed. 
The more advanced thermochemical approaches such as pyrolysis, gasification and plasma-based technologies have been applied to selected smaller scale waste streams, and attempt to control temperatures and pressures of the process (see Table 1). While the application of pyrolysis at low, mid- and high temperature is mainly possible for wastes, gasification is suitable for all burnable materials. In connection with plasma technology, the elimination of dangerous wastes is done by oxidation, and in this method of reduction the goal is to extract raw material. Plasma-based technology is the least-known process. This process is very suitable for the treatment of organic industrial waste, because over $5,000^{\circ} \mathrm{C}$ even PCBs decompose (Karagiannidis and Malamakis [4]).

Table 1: $\quad$ The more advanced WtE technologies.

\begin{tabular}{|c|c|c|c|c|}
\hline Parameters & Pyrolysis & Gasification & Incineration & $\begin{array}{l}\text { Plasma } \\
\text { treatment }\end{array}$ \\
\hline Temperature $\left[{ }^{\circ} \mathrm{C}\right]$ & $250-900$ & $500-1800$ & $800-1450$ & $>2000$ \\
\hline Pressure [bar] & 1 & $1-45$ & 1 & 1 \\
\hline Atmosphere & Inert/nitrogen & $\begin{array}{l}\text { Gasification } \\
\text { agent: } \\
\mathrm{O}_{2}, \mathrm{H}_{2} \mathrm{O}\end{array}$ & Air & $\begin{array}{l}\text { Gasification } \\
\text { agent: } \\
\mathrm{O}_{2}, \mathrm{H}_{2} \mathrm{O} \\
\text { Plasma gas: } \\
\mathrm{O}_{2}, \mathrm{~N}_{2}, \mathrm{Ar} \\
\end{array}$ \\
\hline Products & $\begin{array}{l}\mathrm{H}_{2}, \mathrm{CO}, \\
\mathrm{H}_{2} \mathrm{O}, \mathrm{N}_{2}, \\
\text { hydrocarbons } \\
\text { Ash, coke } \\
\text { Pyrolysis oil } \\
\text { water }\end{array}$ & $\begin{array}{l}\mathrm{H}_{2}, \mathrm{CO}, \mathrm{CO}_{2}, \\
\mathrm{CH}_{4}, \\
\mathrm{H}_{2} \mathrm{O}, \mathrm{N}_{2} \\
\text { Slag, ash }\end{array}$ & $\begin{array}{l}\mathrm{CO}_{2}, \mathrm{H}_{2} \mathrm{O}, \\
\mathrm{O}_{2}, \\
\mathrm{~N}_{2} \\
\text { Slag, ash }\end{array}$ & $\begin{array}{l}\mathrm{H}_{2}, \mathrm{CO}, \\
\mathrm{CO}_{2}, \mathrm{CH}_{4}, \\
\mathrm{H}_{2} \mathrm{O}, \mathrm{N}_{2} \\
\text { Slag, ash }\end{array}$ \\
\hline
\end{tabular}

The emission levels will be sensitive to the accidental inclusion of waste (emission limits are given in the Waste Incineration Directive). The main issue is syngas cleaning. The main constituents in syngas are hydrogen, carbon monoxide, carbon dioxide and methane. If syngas cleaning is omitted, the level of post-combustion emissions requiring capture will be greater. Dioxins will be reduced but not eliminated by syngas cleaning. They are destroyed by higher temperature, but can re-form once the temperature drops. Gasification plants produce large quantities of carbon dioxide and, if the syngas output is used for electricity generation only, and many times greater, on a power for power comparison basis, than a conventional power plant. Gas engines and turbines typically have low tolerances to impurities in the syngas (Hill and Dowen [5]). With pyrolysis the emission of heavy metals is lower (due to lack of oxygen), but one of the disadvantages is that the use of pyrooil is accompanied by significant emissions. Besides this, pyrolysis produces a large quantity of pyrocoke with a high concentration of heavy metals in the cinders. Plasma-based technology has a low gas flow, fast warming and cooling. At the end of the process, with 
minimal environmental effects, materials of glass and ceramics can be obtained, which can be utilised in the building industry (Hogg [6]).

The new technologies differ from the traditional incineration processes in that chemical energy is recovered from the waste. The derived chemical products may be used as feedstock for other processes or as secondary fuel in some cases. The waste is converted into a secondary energy source (a combustible liquid, gas or solid fuel), while it is utilised e.g. in a steam turbine, gas turbine or gas engine in order to produce heat and/or electricity. Smaller fuel gas volumes allow reduced gas cleaning equipment sizes. Furthermore, the new technologies enable a greater market penetration, since these secondary energy sources are compatible with gas turbines and gas motors (Helsen and Bosmans [2]). As for gasification, a disadvantage is that the calorific value of the synthesis gas is below that of natural gas. Therefore, the energy necessary for the operation is more than the energy content of the gas produced. In simple terms, this means that for every 5 units of energy in the waste feedstock, only 1 will emerge as electric power. Gasification can be used in conjunction with higher efficiency energy recovery technologies; however, because the higher efficiency modes of energy recovery are less proven, the financial and environmental benefits are offset by the increased risk. Where pyrolysis and gasification $(\mathrm{P} \& \mathrm{G})$ processes are integrated with more efficient energy recovery, significant greenhouse gas savings per $\mathrm{kW}$ of electricity generated are possible relative to incineration (Hill and Dowen [5]).

\section{Application of the LCA method with software GaBi 5}

Before new technologies enter the market, however, their environmental superiority over competing options must be asserted based on a life-cycle approach. Life cycle assessment investigates the environmental impacts of systems, processes or products. LCA models the complex interaction between a product and the environment from cradle-to-grave throughout the full life cycle, from the exploration and supply of materials and fuels, to the production and operation of the investigated objects, to their disposal/recycling (Pehnt [1]). The life cycle assessment method is one of the best methods for innovation in the area of enviro-management.

The LCA method is usually applied to comparative analysis, when it is possible to choose among the products, processes, services and systems having the same function, but each of them having significantly different environmental effects. The first results of this method came to the surface during energetic analysis and modelling (Bilitewsky et al. [7]). The main phases of an LCA are in Fig. 1.

There are several databases betting continuously refined and expanded but adequate coverage of the processes concerned has not been completed yet. 'LCA addresses the environmental aspects and potential environmental impacts (e.g. use of resources and the environmental consequences of releases) throughout a product's life cycle from raw material acquisition through production, use, endof-life treatment, recycling and final disposal (i.e. cradle-to-grave)' 


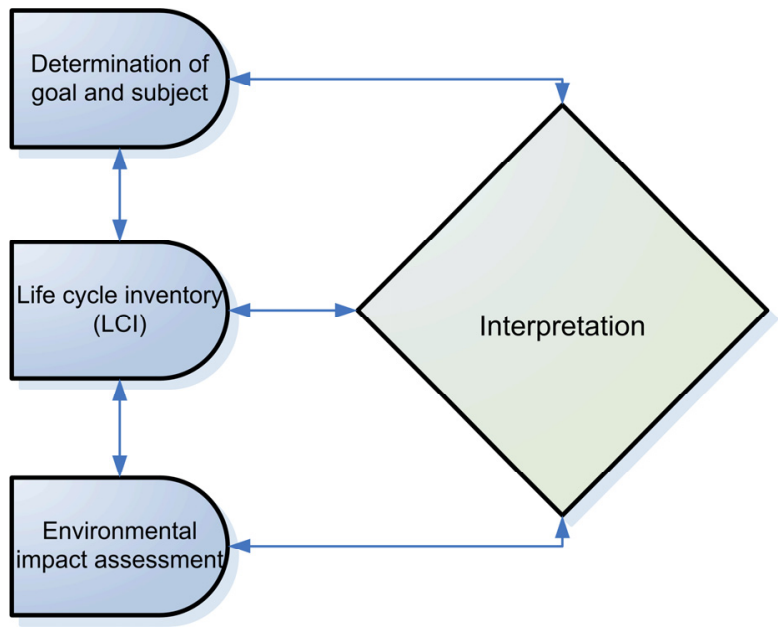

Figure 1: The main phases of the LCA method.

(see ISO14040:2006). In the evaluation, it is required to take the environmental effects of human health into account, as well as the ecosystem or abiotic, depletion. The impact categories include emission of green-house gases global warming, eutrophication and acidification. The importance of several impact categories can be seen in Table 2. Global warming potential is the most important category, and its weighting factor is 10 . The Economic Input-Output

Table 2: $\quad$ Impact categories of the CML 2001 method.

\begin{tabular}{|c|c|}
\hline Impact Categories & Reference \\
\hline Global Warming Potential (GWP) & $\mathrm{kg} \mathrm{CO}_{2}$ - Equiv. \\
\hline Acidiphication Potential (AP) & $\mathrm{kg} \mathrm{SO}_{2}$ - Equiv. \\
\hline Eutrophication Potential (EP) & $\mathrm{kg}$ phosphate- Equiv. \\
\hline Human Toxicity Potential (HTP) & $\mathrm{kg} \mathrm{DCB}$ - Equiv. \\
\hline Photochemical Ozone Creation Potential (POCP) & $\mathrm{kg}$ ethylene- Equiv. \\
\hline Ozone Layer Depletion Potential (ODP) & $\mathrm{kg} \mathrm{R11-} \mathrm{Equiv.}$ \\
\hline Primary Energy & $\mathrm{MJ} \mathrm{kg}$ SB-Equiv. \\
\hline Terrestric Ecotoxicity Potential (TETP) & $\mathrm{kg} \mathrm{DCB}$ - Equiv. \\
\hline Marine Ecotoxicity Potential (MAETP) & $\mathrm{kg} \mathrm{DCB}$ - Equiv. \\
\hline Freshwater Aquatic Ecotoxicity Potential (FAETP) & $\mathrm{kg} \mathrm{DCB}$ - Equiv. \\
\hline
\end{tabular}


Life Cycle Assessment (EIO-LCA) method estimates the materials and energy resources required for, and the environmental emissions resulting from, activities in our economy. This method was theorised and developed by economist Wassily Leontief in the 1970s based on his earlier input-output work from the 1930s, for which he received the Nobel Prize in Economics. The Life Cycle Cost Analysis (LCCA) is a method for assessing the total cost of the facility. It takes into account all costs of acquiring, owning, and disposing of a building or building system. LCCA is especially useful when project alternatives fulfil the same performance requirements, but differs with respect to initial and operating costs and these have to be compared in order to select the one that maximises net savings. A complete life cycle cost analysis may also include other costs, as well as other accounting/financial elements (such as discount rates, interest rates, depreciation, present value of money, etc.) (Cooper et al. [8], Hsu [9]).

The GaBi 5 LCA Software that largely encourages the research work came into the market in November 2011 and has several advantages for its former versions. The GaBi 5 Software with databases 2011 establishes Life Cycle Assessment as an essential tool to develop more sustainable products and processes while increasing resource efficiency, reducing material, energy and cost. GaBi 5 is the next generation product sustainability solution with a powerful Life Cycle Assessment engine to support the Life Cycle Assessment, the Life Cycle Costing, the Life Cycle Reporting and the Life Cycle Working Environment applications. The method of eco-design by LCA develops products with smaller environmental footprints such as fewer GHG emissions, reduced water consumption and waste. GaBi 5 models every element of a product or system from a life cycle perspective and provides an easily accessible content database detailing the energy and environmental impact of sourcing and refining every raw or processed element of a manufactured item. A new database engine for $\mathrm{GaBi} 5$ incorporates world-leading product sustainability intelligence; analyzing and interpreting global LCA databases. GaBi 5 has an intuitive graphical user interface (GUI), which combines built-in complex functionality algorithms, product-modeling, reporting, analytics, scenario planning and communications enhancements - all designed specifically to help responsible businesses minimise their overall environmental impact by saving resources, reducing their emissions, pollution and energy footprint as well as reducing complexity and cutting costs.

\section{Experimental results}

Incineration, pyrolysis, plasma-based technologies and gasification can be considered on the basis of three viewpoints of examination, namely, load of environment, energy efficiency and economic viewpoints (e.g., usefulness, reliability, financial benefits, cost efficiency, payback period). Application with these viewpoints a complex mathematical model for the thermic treatment processes was carried out, which beside of the parameters examined by LCA method, considers time and probability at the same time. 
Within the special program system of MATLAB (Matrix Laboratory) based on the background of the pure mathematical statistics (relative frequencyprobability), each and every environmental effect would mean the aleatory variable of a thermal treatment process - within an operational process. The main key-questions, test parameters and possible methods of the developed complex model can be the following (see Table 3).

Table 3: Main key-questions, test parameters and possible methods by the complex model.

\begin{tabular}{|c|c|c|c|}
\hline & Load of environment & Energy efficiency & Economic efficiency \\
\hline & $\begin{array}{l}\text { - Emissions } \\
\text { - Environmental } \\
\text { reliability } \\
\text { - Treatment of } \\
\text { residual materials }\end{array}$ & - Energetic usefulness & $\begin{array}{l}\text { - Extraction and } \\
\text { utilization of raw } \\
\text { materials } \\
\text { - Recirculation in the } \\
\text { technology } \\
\text { - Costs and cost } \\
\text { efficiency } \\
\text { - Pay-out period }\end{array}$ \\
\hline & $\begin{array}{l}\text { - Input-output } \\
\text { balance of material } \\
\text { - Emissions in } \mathrm{CO}_{2^{-}} \\
\text {Equiv. } \\
\text { - Other and toxic } \\
\text { emissions }\end{array}$ & $\begin{array}{l}\text { - Input-output balance } \\
\text { of energy } \\
\text { - Quantity of the energy } \\
\text { efficiency } \\
\text { - Improving and } \\
\text { retarding coefficients } \\
\text { for the energy } \\
\text { efficiency }\end{array}$ & $\begin{array}{l}\text { - Input-output balance } \\
\text { of energy and } \\
\text { material } \\
\text { - Amount of } \\
\text { recovery/utilization } \\
\text { - Initial, maintenance } \\
\text { and other costs }\end{array}$ \\
\hline $\begin{array}{l}0 \\
0 \\
0 \\
0 \\
0 \\
0 \\
0 \\
0 \\
0 \\
0 \\
0\end{array}$ & $\begin{array}{l}\text { - Material balance } \\
\text { equations and } \\
\text { technological } \\
\text { layout } \\
\text { - Sankey diagram } \\
\text { - Life Cycle } \\
\text { Assessment } \\
\text { - EIO-LCA } \\
\text { (Economic Input- } \\
\text { Output Life Cycle } \\
\text { Assessment) }\end{array}$ & $\begin{array}{l}\text { - Energy balance } \\
\text { equations and } \\
\text { technological layout } \\
\text { - Sankey diagram } \\
\text { - Life Cycle Assessment } \\
\text { (LCA) } \\
\text { - EIO-LCA (Economic } \\
\text { Input-Output Life } \\
\text { Cycle Assessment) }\end{array}$ & $\begin{array}{l}\text { - Material and energy } \\
\text { balance equations } \\
\text { and technological } \\
\text { layouts } \\
\text { - Cost analysis } \\
\text { - Cost efficiency } \\
\text { analysis } \\
\text { - Life Cycle Cost } \\
\text { (LCC) Life-Cycle } \\
\text { Cost Analysis } \\
\text { (LCCA) }\end{array}$ \\
\hline
\end{tabular}

In case of the traditional incineration it would also be worth carrying out an examination with a wider spectrum, and besides recoverable energy (and, of course, relief of dumps), attention should be paid to the emission and other alternatives of utilisation (Mannheim [10]). In order to do so, data from manufacturers and system operators are compiled with the help of the GaBi database and complemented with data from different LCA literature. The general process scheme of the material- and energy scale related to the thermic treatment methods is shown in Figures 2-3. 


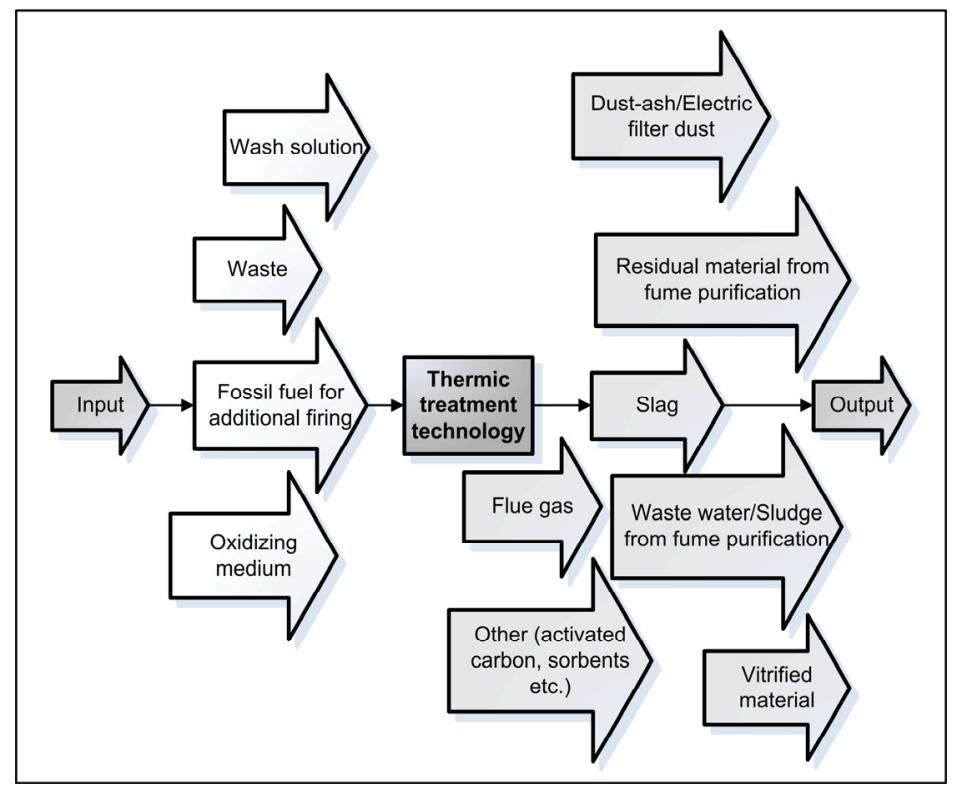

Figure 2: Input-output balance of material for WtE technologies.

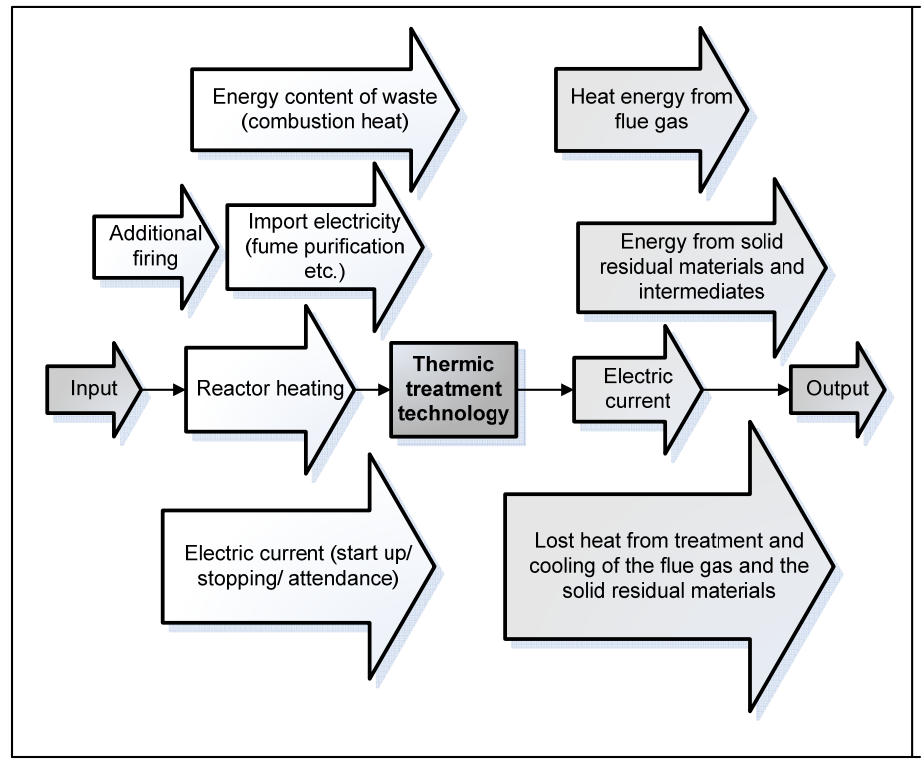

Figure 3: Input-output balance of energy for WtE technologies. 


\section{LCA results for thermic treatments}

The LCA data represents the conventional incineration (with grate firing), the gasification and the pyrolysis for hazardous waste (with PCBs) in the EU 27 with application of GaBi 5 LCA-software. The inventory data for the system must be mathematically normalized to a functional unit, which has to be set a priori and is not a decision variable. The complex system with LCA method is for $1000 \mathrm{~kg}$ hazardous waste with energy recovery. The allocation is applied and the substitution factor used is 1 to 1 . The calorific values are calculated from the elementary composition of hazardous wastes (database November, 2011). The remaining heat is assumed to be used completely. The emissions to air are included in the system. Field landfilling of residues and hazardous wastes is included in the system. The wastes are not transported in this model. Incineration, gasification and pyrolysis of $1 \mathrm{~kg}$ hazardous waste thus yield 2,361 $\mathrm{kWh}$ caloric powers. For the calculation of the mass balance of the process, all input components are split into their composition.

By conventional incineration $\left(1150^{\circ} \mathrm{C}\right)$ the main constituents of syngas are: $\mathrm{NO}_{2}(71,37 \%), \mathrm{CO}_{2}(13,38 \%), \mathrm{SO}_{2}(11,15 \%), \mathrm{HCl}(3,56 \%), \mathrm{CH}_{4}(0,44 \%)$, heavy metals and dioxins $(0,10 \%)$. Dioxins will be not eliminated by syngas cleaning. Due to the contamination with heavy metals, the ash and slag go to landfill for hazardous waste. $1000 \mathrm{~kg}$ hazardous waste burnt can be expected, based on its carbon content, to produce $230 \mathrm{~kg}$ slag, $45 \mathrm{~kg}$ soot and $725 \mathrm{~kg}$ syngas. The heat output is used for electricity generation and thermal convection. The complex process will be used $78 \mathrm{kWh}$ of electrical power and $23,5 \mathrm{kWh}$ of thermal energy from natural gas. The input streams to the system are hazardous waste input, thermal energy from natural gas, electricity and water for flue gas cleaning. Output streams leaving the system as solid materials are ash and slag. The emissions to the atmosphere contained in the clean gas come from the flue gas purification. The auxiliary materials used for the flue gas precipitation in the waste incineration plant are lignite, ammonia and lime. According to measurements for Global Warming Potential (GWP) can be determine 0,707 kg $\mathrm{CO}_{2}$-Equiv. for the incineration. The value of the Ozone Layer Depletion Potential (ODP) is $0,1 \mathrm{~kg}$ R11-Equiv. and the Acidification Potential (AP) is $0,259 \mathrm{~kg} \mathrm{SO}_{2}$-Equiv. Dioxins will be not eliminated by syngas cleaning.

By gasification $\left(1200^{\circ} \mathrm{C}\right)$ will be used $50 \mathrm{kWh}$ of electrical power for the complex process. The input streams to the system are hazardous waste input, natural gas (only by start) and electricity. Output streams leaving the system as solid materials are ash and slag. The Global Warming Potential (GWP) is $0,989 \mathrm{~kg} \mathrm{CO} \mathrm{CO}_{2}$-Equiv. for the gasification. The value of the Ozone Layer Depletion Potential (ODP) is 4E-5 kg R11-Equiv. and the Acidification Potential (AP) is $0,18 \mathrm{~kg} \mathrm{SO}_{2}$-Equiv.

By pyrolysis $\left(500^{\circ} \mathrm{C}\right)$ the input streams to the system are hazardous waste input and electricity $(70 \mathrm{kWh})$. Output streams leaving the system are pyrolysis coke, pyrolysis oil and pyrolysis gas. The Global Warming Potential (GWP) is 
$1,54 \mathrm{~kg} \mathrm{CO}_{2}$-Equiv. for the gasification. The value of the Ozone Layer Depletion Potential (ODP) is $0,0032 \mathrm{~kg} \mathrm{R} 11$-Equiv. and the Acidification Potential (AP) is $0,376 \mathrm{~kg} \mathrm{SO}$-Equiv. The LCA results for the thermic treatments are shown in Figures 4-6.

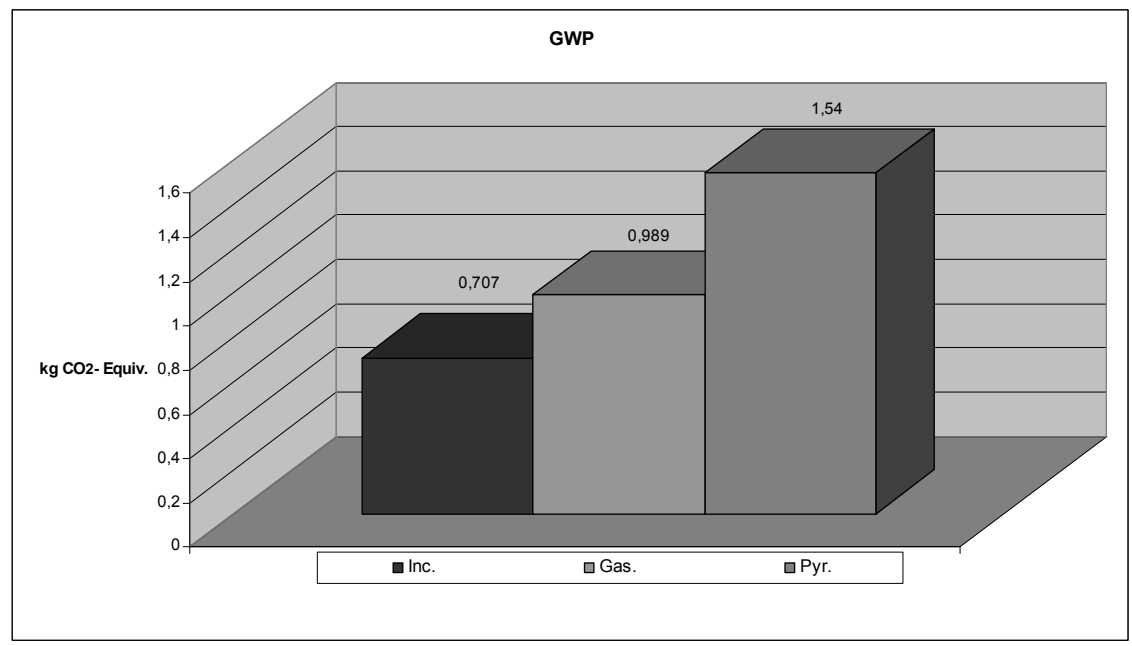

Figure 4: $\quad$ The global warming potential (GWP) for WtE technologies.

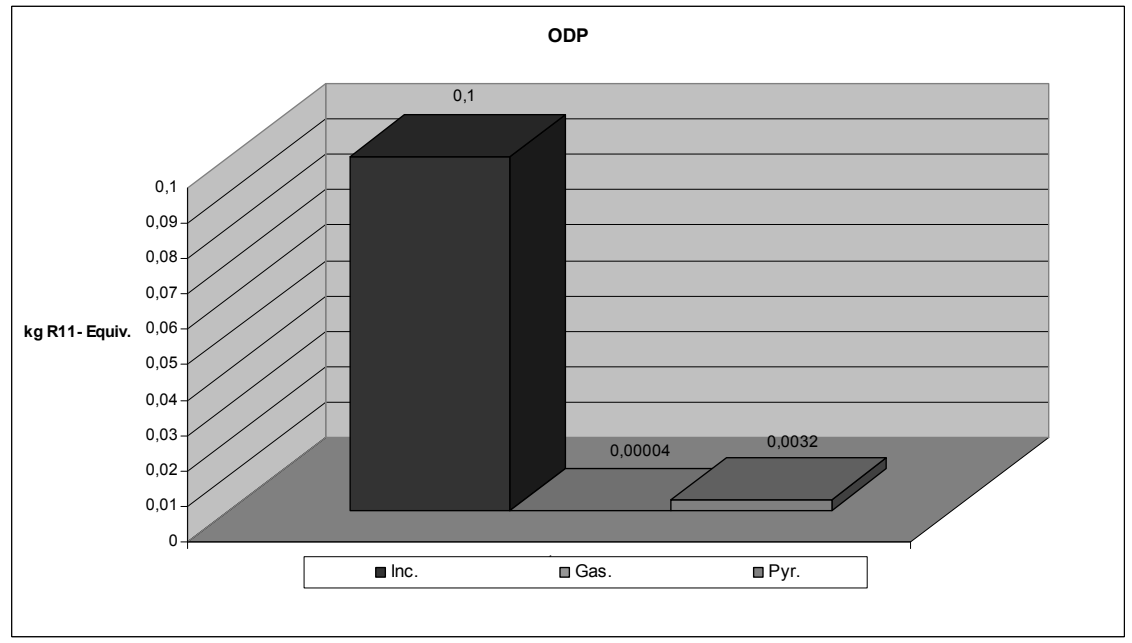

Figure 5: The ozone layer depletion potential (ODP) for WtE technologies. 


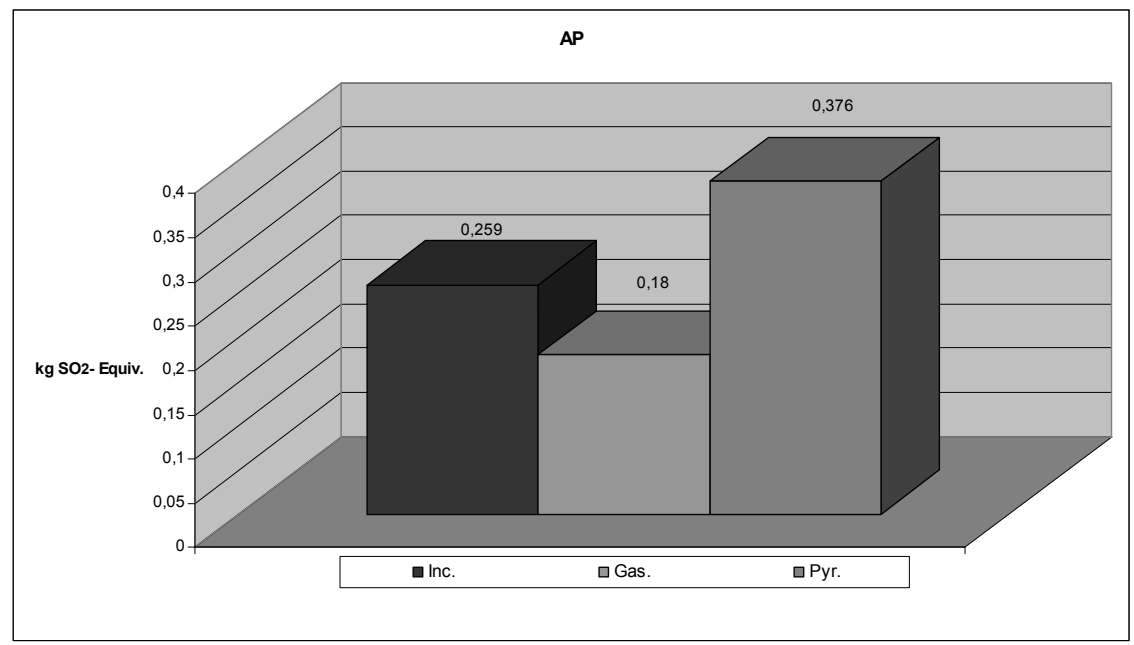

Figure 6: The acidification potential (AP) for WtE technologies.

The investigations show that by incineration the Global Warming Potential (GWP) is better but the Ozone Layer Depletion Potential (ODP) and the Acidification Potential (AP) are higher by this thermic treatment. According to the load of environment can be determined that the gasification by $1200^{\circ} \mathrm{C}$ is the most environmentally friendly technology.

\section{Discussion and conclusions}

In the last few years, several waste energetic utilisation/thermic treatment technologies have come to the front and have been declared to be the best available techniques. The priority of the energetic utilisation of different types of waste remains ambiguous even today. In fact, it all depends on what type of waste is being treated thermally; therefore it is not the energy content that is the decisive factor. Thus, in the case of combustible industrial organic waste, for example, the criterion of energy content is obviously of secondary importance; the most important viewpoint is that the least possible harmful material (e.g. end gas containing unabsorbed chlorine derivates) should remain at the end of the process. This paper summarises thermic utilisation processes with a comparison between the different technologies, stressing factors affecting their applicability and operational suitability. The research study can set up prognoses and models with LCA analyses and the conscious application of scientific methods, which can offer a prognosis for untested situations. Despite the fact that chemical industry and environmental protection are closely interlocked, there is fairly poor national and international professional literature available about the two connected professions. Pyrolysis, incineration and gasification can be considered on the basis of three viewpoints: environmental burden, energy efficiency and economic viewpoints. While examining the above mentioned viewpoints, it 
worked out a new mathematical method which, in addition to the LCA, takes time and probability into consideration with the combination of a programming language, and which may mark a new direction for solutions and decision making in waste management. Combining the different LCA software with mathematical programming languages, a new and effective solution-decision trend can be set for chemical environment protection and for the issues of the management of wastes from chemical processes. This study was reviewed and published in 2012 with the application of new LCA GaBi 5 software (disposability in November 2011). The data records used are based on measurements made on Hungarian plants and calculated data. There is not plasma-based technology in Hungary, so this study can not determine LCA results for this technology at the moment.

\section{Acknowledgements}

The described work was carried out as part of the TÁMOP-4.2.1.B-10/2/KONV2010-0001 project in the framework of the New Hungarian Development Plan. The realization of this project is supported by the European Union, co-financed by the European Social Fund.

\section{References}

[1] Pehnt, M.: Dynamic life cycle assessment (LCA) of renewable energy technologies. Renewable Energy 31, pp. 55-71. 2006.

[2] Helsen, L. and Bosmans, A.: Waste-to-energy through thermochemical processes: matching waste with process. Proceedings of the International Academic Symposium on Enhanced Landfill Mining, HouthalenHelchteren, Belgium, pp. 133-180. 2010.

[3] Young, G.C.: Municipal solid waste to energy conversion processes: Economic, technical, and renewable comparisons. John Wiley \& Sons, Inc., New Jersey. 2010.

[4] Karagiannidis, A. and Malamakis A.: Inventorying the available biomass potential in the region of central Macedonia, Greece. Perspectives for energetic utilization. Proceedings of the 3rd Conference of Aristotle University's Environmental Council on "Climate change, sustainable development and renewable energy sources", Thessaloniki, Greece, pp. 521-529. 2009.

[5] Hill, T. and Dowen, S.: Pyrolysis and gasification, Briefing (Draft 2), UK Without Incineration Network (UKWIN). Available electronically at http://www.ukwin.org.uk. 2010.

[6] Hogg, R.: Energy from waste by pyrolysis and gasification the experience and performance of an operational plant. Proceedings of the International Conference on Sustainable Solid Waste Management, Chennai, India, pp. 385-392. 2007.

[7] Bilitewsky, B., Härdtle, G., Marek, K., Weissbach, A. and Boeddicker, H., Waste Management. Verlag Springer, Berlin, Germany. 1994. 
166 Waste Management and the Environment VI

[8] Cooper, J.S., Godwin, C. and Hall, E.S.: Modeling process and material alternatives in life cycle assessments. International Journal of Life Cycle Assessment 13 (2), pp. 115-123. 2008.

[9] Hsu, D.D.: Life cycle assessment of gasoline and diesel produced via fast pyrolysis and hydroprocessing. Technical Report, NREL/TP/-6A20-49341, Colorado. Available electronically at http://www.osti.gov/bridge. 2011.

[10] Mannheim, V.: LCA in the waste management, in: Csevár, A. (Ed.), Hulladékgazdálkodási Tanácsadó. Verlag Dashöfer, Budapest, Hungary, pp. 187-195. 2010. 